\title{
Irisin interaction with adipose tissue secretions by exercise training and flaxseed oil supplement
}

\author{
Hossein Shirvani ${ }^{1^{*}}$ (D) and Saleh Rahmati-Ahmadabad²
}

\begin{abstract}
Background: Previous studies have shown that physical training and natural diet able to change the expression and concentration of peptides and proteins. Myokines and adipokines play an important role in metabolism and metabolic syndrome. Therefore, the purpose of the present study was to investigate the effect of high-intensity interval training (HIIT) and supplementation of flaxseed oil on plasma irisin, nesfatin-1 and resistin in male rats.

Methods: Forty adult male rats were randomly divided into four groups (ten in each group) including Control-Saline (CS), Training-Saline (TS), Control-FlaxOil supplement (CO), and Training-FlaxOil supplement (TO). The training groups performed for 10 weeks and 5 sessions each week, interval training with 90-95\% VO2max on rodent treadmill, and supplement groups received flaxseed oil $(300 \mathrm{mg} / \mathrm{kg}$ ). Five days after the last training session, rats were sacrificed. Blood samples were taken from the heart and plasma was evaluated.

Results: Exercise Training significantly increased plasma levels of irisin $(P=0.019)$, nesfatin-1 $(P=0.01)$, and decreased resistin $(P=0.01)$. Flaxseed oil significantly reduced plasma resistin levels $(P=0.02)$. Plasma irisin levels in the supplementation group were higher than all groups $(P=0.041)$.

Conclusion: There was a significant positive correlation between plasma levels of irisin with nesfatin-1 and negative correlation with resistin. HIIT program with flaxseed oil as a modality can create a metabolic crosstalk between skeletal muscle and adipose tissues and have health benefits.
\end{abstract}

Keywords: Adipokines, Flaxseed oil supplement, High intensity interval Tarining (HIIT), Metabolic crosstalk, Myokines

\section{Background}

Adipose and skeletal muscle tissues produce various cytokines and their interaction can potentially alter cell metabolism [1, 2]. Irisin is a remarkable myokine/adipokine/ neurokinin that has recently attracted the attention of researchers [3]. Irisin secretion improves metabolic syndrome and glycemia [4]. Skeletal muscle irisin induces muscle hypertrophy [5], and also acts on other tissues such as adipose tissues and induces weight loss by converting white fat into brown fat [6]. The mechanism of the effects of irisin on adipose tissue is has not been clearly understood. A previous study [7] showed that irisin affects white adipocytes via browning genes including Uncoupling

\footnotetext{
* Correspondence: shirvani@bmsu.ac.ir

${ }^{1}$ Exercise Physiology Research Center, Life Style Institute, Baqiyatallah

University of Medical Sciences, Nosrati alley, Sheikh Bahaei Street, Mollasadra

Street, Vanak Square, Post Office Box: 19395-5487, Tehran, Iran

Full list of author information is available at the end of the article
}

Protein 1 (UCP1), Cell Death-Inducing DFFA-Like Effector A (CIDEA), CarnitinePalmitoyltransferase 1B (CPT1B), and Deiodinase, Iodothyronine Type 2 (DIO2). In the present study, we suggest and thus examine the effect of irisin on adipose tissue via changes in energy balance peptide such as nesfatin and resistin. Nesfatin-1 and resistin are important adipokines that act like irisin in affecting weight loss, insulin resistance and metabolic syndrome [8]. Thus, the first aim of this study was the evaluation of the correlation between muscle irisin with adipose tissue nesfatin-1 and resistin.

Previous studies have shown that physical training and the use of natural substances can affect the gene expression and plasma levels of proteins, peptides, and hormones $[9,10]$. With regard to physical activity, studies have shown that different modes of physical activity can alter the expression of tissue/plasma irisin [11], nesfatin-1 
[12] and resistin [13]. In recent times, high-intensity interval training (HIIT) is a novel and enjoyable type of exercise training [14]. It has been reported that HIIT affects exercise capacity, endocrine hormones, and fat mobilization due to its lower time requirement compared to other types of training [15]. There is a dearth in researches on the effect of HIIT on irisin, nesfatin-1, and resistin. Thus, this study also aims at evaluating the effects of HIIT on irisin, nesfatin-1, and resistin. With regard to natural substances, flaxseed is rich in omega-3 $(\omega-3)$ fatty acid, $\alpha$-linolenic acid (ALA) and phytoestrogen lignans [16]. Fibers and ligands of flaxseed have been reported to have beneficial health effects such as weight loss and reduced metabolic disorders $[17,18]$. To the best of the author's knowledge, there have been no research on the effects of flaxseed on irisin, nesfatin-1, and resistin, hence, this study also examined this effect. In summary, the combination of exercise with natural substances may have a varied effect than exercise or natural substances alone. Overall, the aim of the present study was to investigate the effects of HIIT with and without flaxseed oil on plasma irisin, nesfatin-1, and resistin concentration, in addition to their interaction on plasma irisin, nesfatin-1 and resistin.

\section{Methods}

\section{Animals}

Forty adult male Wistar rats were randomly selected for the present study.

\section{Ethical considerations}

The present study was conducted with the written consent of the research deputy of Baqiyatallah University. This study was conducted in accordance with National Institutes of Health (NIH) publication and all ethical conventions regarding laboratory animals were considered.

\section{Animal conditions}

Animals were kept in the animal houses of Baqiyatallah University of Medical Science at a temperature of $22 \pm 2$ degrees, humidity $45-50 \%$ and lighting-dark cycle $(12 \mathrm{~h}$ light, $12 \mathrm{~h}$ darkness) in special cages and their palms were covered with clean wood chips. Special compressed food produced by the Behparvar Manufacturing Company in Karaj and urban filtered water in $500 \mathrm{ml}$ bottles, were used for laboratory rats.

\section{Animal groups}

Rats were divided randomly into four groups (ten per group) including Control-Saline (CS), Training-Saline (TS), Control-FlaxOil supplement (CO), and Training-FlaxOil supplement (TO).

\section{Flaxseed oil}

Fresh flaxseeds were collected from growing areas in the city of Mehriz, Yazd Province. The oil was extracted by oil-making machine after approval from the Faculty of Biology (Department of Botany) in Baqiyatallah University and was administered to the rats in the relevant groups based on their weight at a dose of $300 \mathrm{mg} / \mathrm{kg}$. Saline was administered to the other groups. The supplement and saline were administered using oral gavage before the exercise.

\section{Orientation to HIIT}

The orientations of rats were performed with high periodic intense training protocol of 10 practice sessions in 2 weeks. This indicated that on the first day of training, the rats were placed on a treadmill with all precision and comfort. Moreover, it began to practice with a low and even speed. In the next sessions, the rats were joined to the plans in order to be familiar with the periodic protocol that was used with low speeds of periodic exercise. During the 2 weeks, exercise time was increased until the rats reached the real time of main body exercise in $18 \mathrm{~min}$.

\section{Main HIIT protocol}

After 2 weeks, the main exercise began and was completed for 10 weeks. It should be noted that the slope of the treadmill during the whole exercise training was $0^{\circ}$ and familiarity was conducted for the non-exercise groups. At the end of 2 weeks familiarity, VO2 max was estimated in rats. According to the exercise protocol, the first main session began based on the percentage of estimated VO2 max described as $\mathrm{m} / \mathrm{min}$ [19].

Due to lack of direct access to tools such as the respiratory gas analyzing device, the exact method based on a study by Hoydal et al., [19] was performed to describe VO2max as $\mathrm{m} / \mathrm{min}$. This protocol was carefully used as follows: first, warm-up was performed at low speed $(10 \mathrm{~m} / \mathrm{min})$ for $10 \mathrm{~min}$. Afterwarming up, test were conducted with rats running at $15 \mathrm{~m} / \mathrm{min}$ for $2 \mathrm{~min}$ and then treadmill speed was increased every $2 \mathrm{~min}$ at a rate of $0.03 \mathrm{~m} / \mathrm{s}(1.8-2 \mathrm{~m} / \mathrm{min})$ until the animals were not able to run (fatigue stage). The speed in the fatigue stage was estimated as $100 \%$ maximum oxygen consumption (VO2max). Lesser intensity was calculated as a percentage of speed in fatigue stage. For example, if animals were not able to run (fatigue stage) at the speed of $34 \mathrm{~m} / \mathrm{min}, 60 \% \mathrm{VO} 2 \mathrm{max}=60 \% \times 34$. At the end of each 2 weeks, the new speed according to the new estimated VO2max was calculated.

Each session consisted of $30 \mathrm{~min}$ of HIIT as shown in Table 1 . The exercise program included three intensive intervals and low intensity. Intense periods were performed in 90 to $100 \%$ of estimated $\mathrm{VO} 2 \mathrm{max}$ (speed in 
Table 1 High-intensity interval training program

\begin{tabular}{|c|c|c|c|c|}
\hline \multirow[t]{2}{*}{ Steps } & \multirow[t]{2}{*}{ Warm-up } & \multicolumn{2}{|l|}{ Three alternates } & \multirow[t]{2}{*}{ Cool-dowr } \\
\hline & & High-intensity intermittent & Low-intensity intermittent & \\
\hline Time (Minute) & 6 Min & $4 \mathrm{Min}$ & $2 \mathrm{Min}$ & 6 Min \\
\hline Intensity (Vo2max) & 50 to $60 \%$ & 90 to $100 \%$ & 50 to $60 \%$ & 50 to $60 \%$ \\
\hline First \& second week (m/min) & $18-22$ & $32-36$ & $18-22$ & $18-22$ \\
\hline Third \& fourth week (m/min) & $23-27$ & $41-46$ & $23-27$ & $23-27$ \\
\hline Fifth \& sixth week (m/min) & $27-32$ & $48-54$ & $27-32$ & $27-32$ \\
\hline Seventh \& eighth week (m/min) & $30-36$ & $54-60$ & $30-36$ & $30-36$ \\
\hline Ninth \& tenth week (m/min) & $35-41$ & $62-69$ & $35-41$ & $35-41$ \\
\hline
\end{tabular}

fatigue stage) for $4 \mathrm{~min}$ while low intensity periods was performed in 50 to $60 \%$ of estimated VO2max (speed in fatigue stage) for $2 \mathrm{~min}$ [20]. It should be noted that 50 to $60 \%$ of estimated VO2max (speed in fatigue stage) was considered for the warm-up and cool-down sessions. At this moment, a control group for the standardization of the effect of stress was placed on the treadmill for $15 \mathrm{~min}$ at a speed of $2 \mathrm{~m} / \mathrm{min}$. The training protocol continued for 5 days before sacrificing the rats.

\section{Sampling}

Five days after completing the experimental stages of the research, rats were anesthetized using a combination of xylazine (3-5 mg/kg body weight) and ketamine (30-50 $\mathrm{mg} / \mathrm{kg}$ body weight). Blood was collected in EDAT test tubes (anticoagulant) and immediately processed for plasma preparation during $10 \mathrm{~min}$ centrifugation at $1000 \times$ g. Plasma was frozen in liquid nitrogen and stored at $-70 \mathrm{C}$ until they were taken to the laboratory.

\section{Evaluation of variables}

Plasma levels of irisin, nesfatin-1 and resistin were measured by enzyme-linked immunosorbent assay (ELISA) method based on the manufacturer's instructions. For irisin and nesfatin-1 measurement, the ELISA kit, (Bioassay technology Laboratory, China), with sensitivities of 0.03 and $16.23 \mathrm{ng} / \mathrm{ml}$, respectively, was used. The plasma resistin level was measured by Biovendor kit (Biovendor Research and Diagnostic Products, Czech Republic) with a sensitivity of $0.25 \mathrm{ng} / \mathrm{ml}$.

\section{Statistical analyses}

Descriptive statistics were used to categorize and determine dispersion indices. The Kolmogorov-Smirnov test was used to determine data distribution. In order to estimate variations between the groups, the two-way Analysis of Variance (ANOVA) and Tukey Post hoc test were used. The repeated measure ANOVA was used to identify any difference in rats' body mass for the duration of the study. Correlation was calculated with the Pearson Product Moment correlation. All significant levels were considered at $P<0.05$ using the SPSS (Version 19) software.

\section{Results}

There was no difference in body mass $(P=0.376)$ (Table 2). Data analysis showed that there was a significant difference between the research groups regarding plasma irisin $(P=0.01)$. Using post hoc test showed that HIIT significantly increased plasma irisin levels compared to the control group $(P=0.019)$. There was also a significant difference between the control groups and the supplementary-HIIT $(P=0.041)$. Plasma irisin levels were higher in the TS group than $\mathrm{CO}$ group $(P=0.011)$. Plasma irisin levels were higher in the TO group than CO group $(P=0.02)$ (Fig. 1$)$.

In the case of nesfatin-1, data analysis showed a significant difference between the research groups $(P=0.01)$. Using post-test, there was a significant difference between the control and training groups $(P=0.01)$. HIIT significantly increased plasma nesfatin-1 levels compared to the control group (Fig. 2). Plasma nesfatin-1 was significantly higher in TS versus $\mathrm{CO}(P=0.045)$ and TO versus $\mathrm{CO}$ $(P=0.031)$.

Data analysis showed a significant difference between the research groups regarding resistin $(P=0.01)$. Using post hoc test showed a significant difference between CS group with CO $(P=0.048)$, TS $(P=0.011)$ and TO $(P=0.02)$. All groups showed lower plasma resistin levels than control (Fig. 3).

There was a positive and significant correlation between plasma levels of irisin and nesfatin- 1 in TS $(P=0.04$ and $r=0.64)$ and TO groups $(P=0.023$ and $r=0.55)$ (Table 3 ). There was a negative and significant correlation between plasma irisin and resistin TS $(P=0.008$ and $r=-0.62)$ and TO groups $(P=0.018$ and $r=-0.53)$ (Table 3$)$.

\section{Discussion}

The most important findings of this study were 1- HIIT increased plasma levels of irisin, nesfatin-1 and decreased plasma levels of resistin; 2- Flaxseed oil reduced plasma levels of resistin; 3- The interaction between 


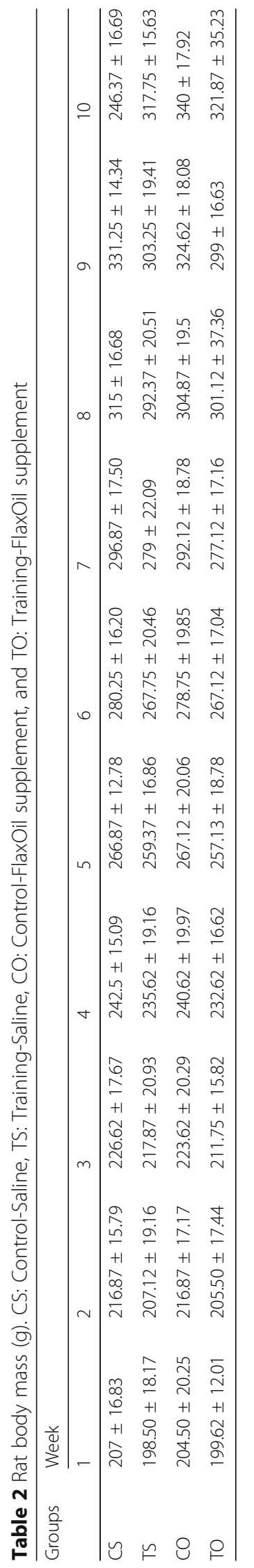




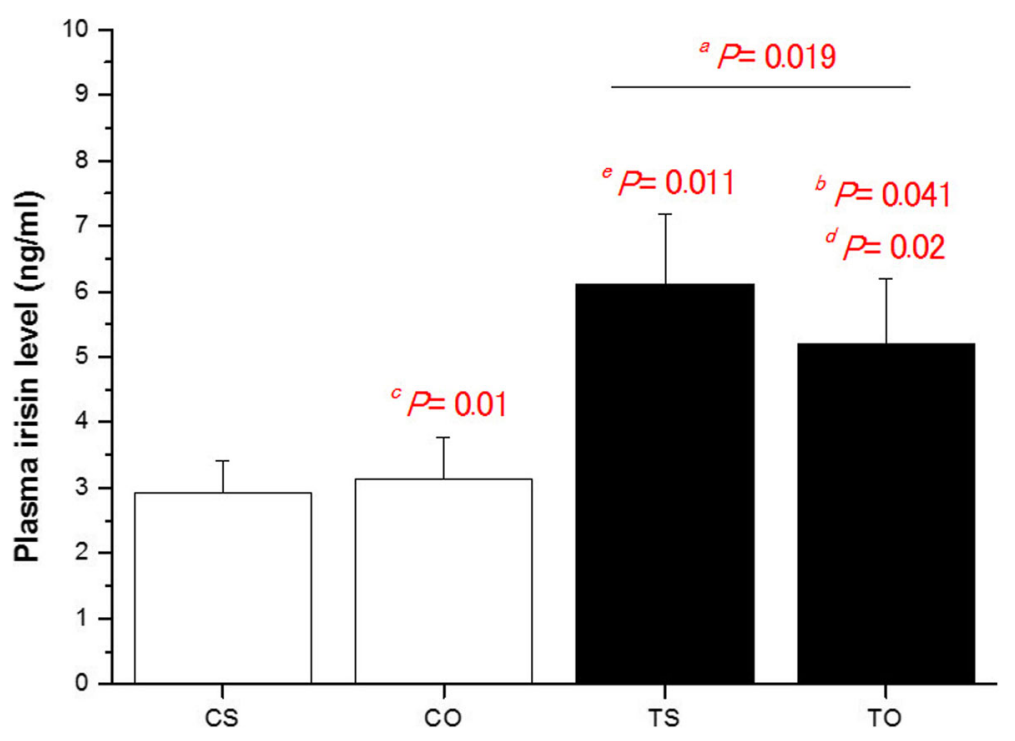

Fig. 1 Data are express as mean \pm standard deviation. CS: Control-Saline, TS: Training-Saline, CO: Control-FlaxOil supplement, and TO: TrainingFlaxOil supplement. The rats are 10 in each group. ${ }^{a}$ Training groups versus sedentary. ${ }^{b}$ Interaction effects of exercise and supplement versus control groups. ${ }^{c} \mathrm{CO}$ versus $\mathrm{CS} .{ }^{d}$ CO versus TO. ${ }^{e}$ TS versus CO

HIIT and flaxseed oil increased the plasma levels of irisin and decreased the plasma levels of resistin; 4- There is a positive and significant correlation between plasma levels of irisin and nesfatin-1; 5- There is a negative and significant correlation between plasma irisin and resistin.

The results of most previous studies indicated that physical training increased irisin. Daskalopoulou et al. [21] Showed that plasma levels of irisin increased in response to increased exercise load in active young people. In a study by Boström et al. [22], they showed that irisin increased after 3 weeks of aerobic training in rats and also resulted in an increase in energy expenditure and improved glucose levels. In addition, Huh et al. [23] showed that after $30 \mathrm{~min}$ of speed activity, irisin levels increased significantly. Research has shown that there are possible mechanisms to indicate how physical activity increases irisin levels. Researches have shown that physical activity increases Peroxisome proliferator-activated receptor gamma coactivator 1-alpha (PGC-1 $\alpha$ ) levels in skeletal muscle and the Fibronectin type III domain-containing protein 5 (FNDC5), the muscle-bearing membrane protein, that leads to irisin production [2]. AMP-activated

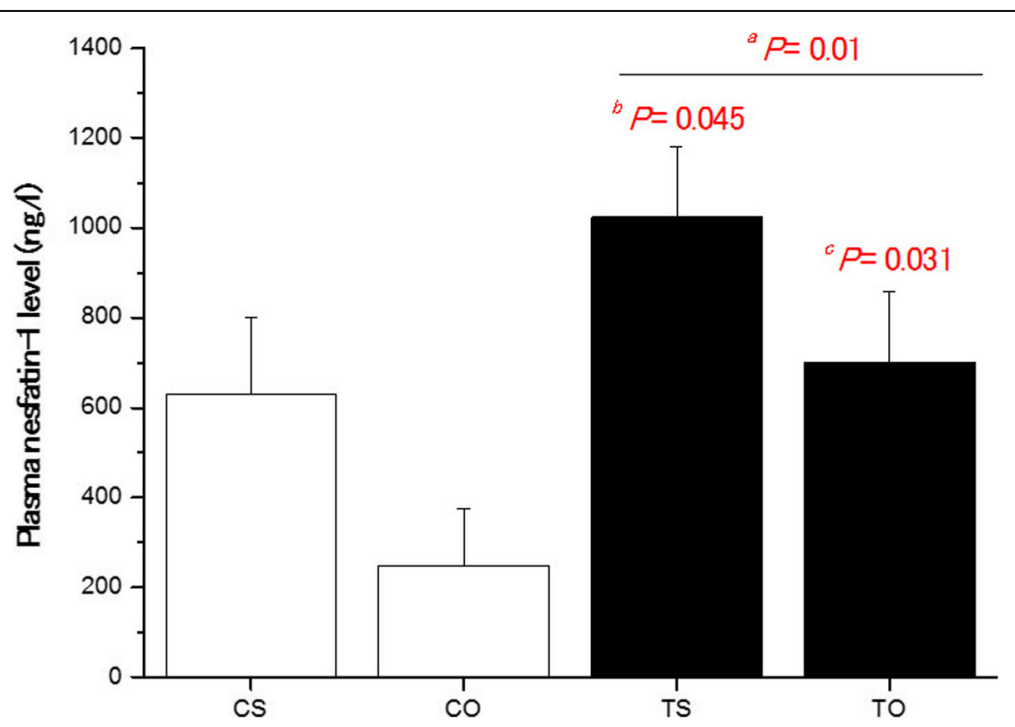

Fig. 2 Data are express as mean \pm standard deviation. CS: Control-Saline, TS: Training-Saline, CO: Control-FlaxOil supplement, and TO: TrainingFlaxOil supplement. The rats are 10 in each group. ${ }^{a}$ Training groups versus sedentary. ${ }^{b}$ TS versus CO. ${ }^{c}$ TO versus CO 


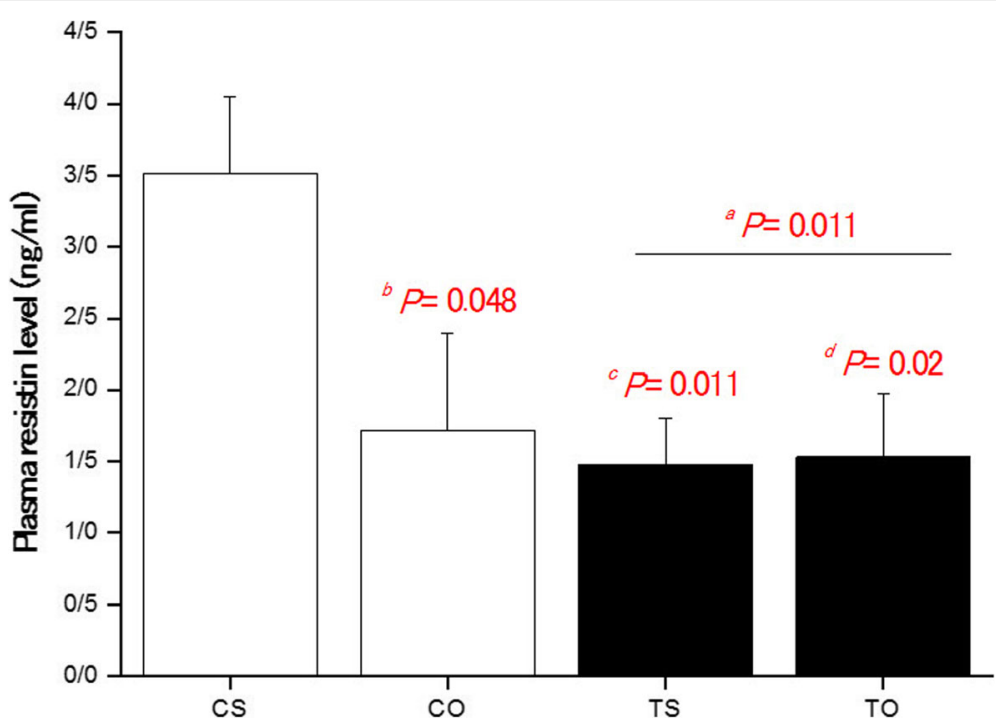

Fig. 3 Data are express as mean \pm standard deviation. CS: Control-Saline, TS: Training-Saline, CO: Control-FlaxOil supplement, and TO: TrainingFlaxOil supplement. The rats are 10 in each group. ${ }^{a}$ Training groups versus sedentary. ${ }^{b}$ CO versus CS. ${ }^{c}$ TS versus CS. ${ }^{d}$ TO versus CS

protein kinase (AMPK's) activation during HIIT is one of the factors that increases PGC-1 $\alpha$ and irisin [24]. AMPK's activation leads to the phosphorylation of PGC- $1 \alpha$ as FNDC5's modifier and irisin secretion [25]. Furthermore, PGC- $1 \alpha$ activates peroxisome proliferator-activated receptor $\gamma($ PPAR $\gamma)$ which is involved in energy metabolism and stimulates FNDC5 and irisin increase [26]. It reported that there is a relationship between irisin levels and precursors of FNDC5 and PGC-1 $\alpha$ [25]. The HIIT probably activates the PGC- $1 \alpha$ activating signals, which also triggers a cascade of signals to change the phenotype of the adipose tissue. HIIT training causes energy consumption and heat production by increasing muscular tissue ratio to fat tissue and increasing UCP1 [24]. Thus, it triggers an increase in PGC-1 $\alpha, \mathrm{FNDC5}$, and irisin [25]. Muscle production and secretion of irisin is also mediated by mothers against decapentaplegic homolog 3 (SMAD3), molecule that modulates energy metabolism and regulate body weight. SMAD3 suppresses FNDC5 and PGC- $1 \alpha$ in skeletal muscle and negatively regulates plasma irisin [27]. Exercise induces phosphorylation

Table 3 Correlation between irisin levels in study groups. CS: Control-Saline, TS: Training-Saline, CO: Control-FlaxOil supplement, and TO: Training-FlaxOil supplement

\begin{tabular}{llllll}
\hline Variables & \multicolumn{2}{l}{ Nesfatin-1 } & & \multicolumn{2}{l}{ Resistin } \\
\cline { 2 - 3 } & $P$ & & & $P$ & $r$ \\
\hline CS & 0.142 & 0.12 & & 0.225 & 0.089 \\
CO & 0.211 & 0.104 & & 0.064 & -0.23 \\
TS & $0.04 *$ & 0.64 & & $0.008 * *$ & -0.62 \\
TO & $0.02{ }^{*}$ & 0.55 & & $0.018 * *$ & -0.53 \\
\hline${ }^{*}<0.05 ; * 0.01$ & & & &
\end{tabular}

${ }^{*}<0.05 ;{ }^{* *}<0.01$ of SMAD2 and subsequently, SMAD3 [27]. In recent years, studies have investigated the effect of physical exercises on nesfatin-1. Ghanbari-Niaki et al. evaluated the effect of 8 weeks of endurance training (5 days a week for $60 \mathrm{~min}$ at $25 \mathrm{~m} / \mathrm{min}$ speed with zero gradient) on tissue nesfatin-1 gene expression and plasma levels of nesfatin-1 [28]. Their results showed that training increased the expression and nesfatin-1 plasma levels, which is related to plasma high-density lipoproteins (HDL) concentration. Nesfatin is involved in the regulation of blood glucose, improves insulin sensitivity, energy homeostasis, and metabolism [29]. The effect of exercise on nesfatin-1 has not been identified clearly and their effects after HIIT have not been studied. However, possible mechanisms exist. Studies have shown that nesfatin-1 is affected by various factors. For example, starvation in rats decreases serum nesfatin-1 levels by up to $18 \%$. On the other hand, it has been reported that nesfatin-1 levels returned to normal levels, 1 to $12 \mathrm{~h}$ after refeeding [29]. In addition, some studies have shown that there is a direct relationship between nesfatin-1 and cortisol levels. In a study by [30], central injection of nesatin-1 increased adrenocorticotropin levels. According to previous studies, all of these factors are higher in the HIIT protocol, which can be considered as a possible cause for increased nesfatin- 1 and as a result, these methods compared studies that did not indicate any changes. The adipose tissue also secretes various inflammatory cytokines that affect the expression and secretion of adipokines. Tumor necrosis factor- $\alpha$ (TNF- $\alpha$ ) is one of these factors that has varying effects on adiponectin, leptin and nesfatin-1. Studies have shown that TNF- $\alpha$, Interleukin 6 (IL-6) and insulin increase the 
intracellular expression of nesfatin-1 in fat-cultured cells [31]. These findings show that the expression and secretion of nesfatin-1 is regulated from different pathways. Some clinical studies have reported that there is a significant relationship between nesfatin-1 and insulin sensitivity [32]. Therefore, it is likely that physical activity, directly or indirectly alters the level of insulin and cortisol, as well as blood glucose. Physical activity also affects nesfatin-1 levels, and consequently, plays a role in improving insulin sensitivity. Although these factors were not investigated in this study, further studies are required in this regard. Concerning resistin, it has been reported that it increases because of obesity and significantly reduces by exercise and caloric restriction [12]. Kadoglou et al. [33] showed that 16 weeks of HIIT had beneficial effects on reducing serum resistin in obese and diabetic men and women. Bludasi et al. [34] showed that 12 months of HIIT reduced serum resistin in diabetic and obese people. Jamali et al. [35] showed that HIIT can reduce resistin gene expression in adipose tissues of obese rats as a pro-inflammatory agent. Thus far, the mechanism that explains the effect of HIIT on resistin has not been determined but possible explanations are available. A previous study showed that regular moderate-intensity physical training suppresses the expression of dual specificity protein phosphatase 1 (DUSP1), increases the expression of PGC-1 $\alpha$ and reduces the activities of $\mathrm{N}$-terminal kinases (JNK) and extracellular signal-regulated kinases (ERK) [36]. They concluded that the effects of anti-inflammatory exercise might be related to the supression of nicotinamide adenine dinucleotide phosphate (NADPH) oxidase, ERK1/2, and stress-activated protein kinases (SAPK)/JNK activities, and increases in superoxide dismutase 1 (SOD-1) gene expression. In our study, we reported decreased resistin levels after 10 weeks of HIT of the beneficial effects of this type of training is similar to regular moderate continuous training.

Another finding of this study is the effect of flaxseed oil supplementation on the irisin and resistin levels. Flaxseed oil increases irisin levels. On the other hand, plasma resistin levels were decreased in response to flax seed oil. Thus far, a direct study has not investigated the effects of flaxseed oil on irisin and resistin, and there is no specific mechanism. It is well stablished that fruits, vegetables, and herbal plants are useful due to their components. For example, carotenoids (fat-soluble pigments) produced by plants and microorganisms and highly present fruits, vegetables, seaweeds and some seafood and a fundamental component of Mediterranean foods, are already known to decrease the incidence and prevalence of cardiovascular events, perhaps via their antioxidant action on free radicals or by acting as anti-inflammatory molecules $[37,38]$. It has been shown that amelioration in calculated Framingham Risk Score in patients suffering from metabolic syndrome and undergoing nutraceutical administration [39]. Nutraceuticals (a food or part of a food that provides medical or health benefits, including the prevention and/or treatment of a disease [40]) are able to interact with several biochemical pathways in lipid metabolism [37]. Flaxseed oil contains a plant-based omega-3, alpha-linolenic acid (ALA), thus, the effects of flaxseed oil on irisin and resistin may related to $\omega-3$. In a study by Ansari et al. [41], the use of omega-3 supplementation at $1250 \mathrm{mg}$ three times daily increased irisin serum levels in diabetic patients. Vaughan et al. [42] showed that omega-3 consumption increased the expression of PGC- $1 \alpha$ genes and skeletal muscle irisin. Tortosa-Caparros et al. [43] revealed that omega- 3 and -6 consumption decreased cardiovascular disease by reducing resistin. Mostowik et al. [44] reported $11.3 \%$ decrease in resistin after omega-3 consumption which is associated with a reduction in coronary heart disease.

\section{Conclusion}

In conclusion, the present study indicated the positive effect of HIIT and flaxseed oil in improving plasma irisin, nesfatin-1 and resistin levels. Probably, these changes are considered as mechanisms for increasing metabolism and reducing metabolic syndrome in patients, and thus require further research. In addition, further investigations into certain mechanisms related to the effects of HIIT and flaxseed oil on irisin, nesfatin-1, and resistin considering DUSP1, PGC- $1 \alpha$, JNK, ERK, NADPH oxidase, SOD-1, SMAD3, FNDC5, and UCPs are required.

\begin{abstract}
Abbreviations
AMPK: AMP-Activated Protein Kinase; CIDEA: Cell Death-Inducing DFFA-Like Effector A; CO: Control-FlaxOil supplement; CPT1B: Carnitine Palmitoyltransferase 1B; CS: Control-Saline; DIO2: Deiodinase, lodothyronine Type 2; ERK: Extracellular signal-Regulated Kinases; FNDC5: Fibronectin Type III Domain-Containing Protein 5; HDL: High-Density Lipoproteins; HIIT: High-Intensity Interval Training; IL6: Interleukin 6; JNK: N-terminal kinases; NADPH: Nicotinamide Adenine Dinucleotide Phosphate oxidase; NIH: National Institutes of Health; PGC1a: Peroxisome Proliferator-Activated Receptor Gamma Coactivator 1-Alpha; PPARY: Peroxisome Proliferator-Activated Receptor $\gamma$; SAPK: Stress-Activated Protein Kinases; SMAD3: Mothers Against Decapentaplegic Homolog 3; SOD1: SuperOxide Dismutase 1; TNF-a: Tumor Necrosis Factor-a; TO: Training-FlaxOil supplement; TS: Training-Saline; UCP1: Uncoupling Protein 1; $\omega$-3: Omega-3
\end{abstract}

\section{Acknowledgments}

The authors express their sincere appreciation and thanks to the Exercise Physiology Research center, Life Style Institute, Baqiyatallah University of Medical Sciences, Tehran, Iran.

Funding

No funding

Availability of data and materials

All data generated or analyzed are included in this paper.

Authors' contributions

HS \& SRA are responsible for the design, experimental analyses, data analysis and interpretation and drafting of the manuscript. Both authors read and approved the final manuscript. 


\section{Ethics approval}

The present study was conducted with the written consent of the research deputy of Baqiyatallah University. This study was conducted in accordance with NIH publication and all ethical conventions regarding laboratory animals were considered.

\section{Consent for publication}

Not applicable.

\section{Competing interests}

The authors declare that they have no competing interests.

\section{Publisher's Note}

Springer Nature remains neutral with regard to jurisdictional claims in published maps and institutional affiliations.

\section{Author details}

${ }^{1}$ Exercise Physiology Research Center, Life Style Institute, Baqiyatallah University of Medical Sciences, Nosrati alley, Sheikh Bahaei Street, Mollasadra Street, Vanak Square, Post Office Box: 19395-5487, Tehran, Iran. ${ }^{2}$ Department of Physical Education, Pardis branch, Islamic Azad University, Pardis, Iran.

\section{Received: 11 October 2018 Accepted: 6 January 2019}

\section{Published online: 17 January 2019}

\section{References}

1. Gorgens SW, Eckardt K, Jensen J, Drevon CA, Eckel J. Exercise and regulation of Adipokine and Myokine production. Prog Mol Biol Transl Sci. 2015;135: 313-36. https://doi.org/10.1016/bs.pmbts.2015.07.002.

2. Schnyder S, Handschin C. Skeletal muscle as an endocrine organ: PGC-1a, myokines and exercise. Bone. 2015;80:115-25. https://doi.org/10.1016/j.bone. 2015.02.008.

3. Roca-Rivada A, Castelao C, Senin LL, Landrove MO, Baltar J, Belen Crujeiras A, Seoane LM, Casanueva FF, Pardo M. FNDC5/irisin is not only a myokine but also an adipokine. PLoS One. 2013;8(4):e60563. https://doi.org/10.1371/ journal.pone.0060563.

4. Lopez-Legarrea P, de la Iglesia R, Crujeiras AB, Pardo M, Casanueva FF, Zulet MA, Martinez JA. Higher baseline irisin concentrations are associated with greater reductions in glycemia and insulinemia after weight loss in obese subjects. Nutr Diabetes. 2014;4:e110. https://doi.org/10.1038/nutd.2014.7.

5. Reza MM, Subramaniyam N, Sim CM, Ge X, Sathiakumar D, McFarlane C, Sharma M, Kambadur R. Irisin is a pro-myogenic factor that induces skeletal muscle hypertrophy and rescues denervation-induced atrophy. Nat Commun. 2017;8(1):1 104. https://doi.org/10.1038/s41467-017-01131-0.

6. Fukushima Y, Kurose S, Shinno H, Thi Thu HC, Takao N, Tsutsumi H, Hasegawa T, Nakajima T, Kimura Y. Effects of body weight reduction on serum Irisin and metabolic parameters in obese subjects. Diabetes Metab J. 2016:40(5):386-95. https://doi.org/10.4093/dmj.2016.40.5.386.

7. Zhang G, Sun Q, Liu C. Influencing factors of thermogenic adipose tissue activity. Front Physiol. 2016;7:29. https://doi.org/10.3389/fphys.2016.00029.

8. Fasshauer M, Bluher M. Adipokines in health and disease. Trends Pharmacol Sci. 2015;36(7):461-70. https://doi.org/10.1016/j.tips.2015.04.014.

9. Ghanbari-Niaki A, Rahmati-Ahmadabad S. Effects of a fixed-intensity of endurance training and pistacia atlantica supplementation on ATP-binding cassette G4 expression. Chin Med. 2013;8(1):23. https://doi.org/10.1186/ 1749-8546-8-23.

10. Shirvani H, Ghanbari-Niaki A, Rahmati-Ahmadabad S, Sobhani V. Effects of endurance training and herb supplementation on tissue nesfatin-1/ nucleobindin-2 and ghrelin mRNA expression. Int J Appl Exer Physiol. 2017;6(1):71-4.

11. Amaro Andrade P, Souza Silveira BK, Corrêa Rodrigues A, Oliveira da Silva FM, Barbosa Rosa CO, Gonçalves Alfenas RC. Effect of exercise on concentrations of irisin in overweight individuals: a systematic review. Science Sports. 2018;33(2):80-9. https://doi.org/10.1016/j.scispo.2017.11.002.

12. Garcia-Hermoso A, Ceballos-Ceballos RJ, Poblete-Aro CE, Hackney AC, Mota J, Ramirez-Velez R. Exercise, adipokines and pediatric obesity: a metaanalysis of randomized controlled trials. Int J Obes. 2017;41(4):475-82. https://doi.org/10.1038/ijo.2016.230

13. Marcelino-Rodriguez I, Almeida Gonzalez D, Aleman-Sanchez JJ, Brito Diaz B, Rodriguez Perez MDC, Gannar F, Dominguez Coello S, Cuevas Fernandez FJ, Cabrera de Leon A. Inverse association of resistin with physical activity in the general population. PLoS One. 2017;12(8):e0182493. https://doi.org/10. 1371/journal.pone.0182493.

14. Foster C, Farland CV, Guidotti F, Harbin M, Roberts B, Schuette J, Tuuri A, Doberstein ST, Porcari JP. The effects of high intensity interval training vs steady state training on aerobic and anaerobic capacity. J Sports Sci Med. 2015;14(4):747-55.

15. Jung ME, Bourne JE, Little JP. Where does HIT fit? An examination of the affective response to high-intensity intervals in comparison to continuous moderate- and continuous vigorous-intensity exercise in the exercise intensity-affect continuum. PLoS One. 2014;9(12):e114541. https://doi.org/10. 1371/journal.pone.0114541.

16. Goyal A, Sharma V, Upadhyay N, Gill S, Sihag M. Flax and flaxseed oil: an ancient medicine \& modern functional food. J Food Sci Technol. 2014;51(9): 1633-53. https://doi.org/10.1007/s13197-013-1247-9.

17. Cassani RS, Fassini PG, Silvah JH, Lima CM, Marchini JS. Impact of weight loss diet associated with flaxseed on inflammatory markers in men with cardiovascular risk factors: a clinical study. Nutr J. 2015;14:5. https://doi.org/ 10.1186/1475-2891-14-5.

18. Machado AM, de Paula H, Cardoso LD, Costa NMB. Effects of brown and golden flaxseed on the lipid profile, glycemia, inflammatory biomarkers, blood pressure and body composition in overweight adolescents. Nutrition. 2015;31(1):90-6. https://doi.org/10.1016/j.nut.2014.05.002.

19. Hoydal MA, Wisloff U, Kemi OJ, Ellingsen O. Running speed and maximal oxygen uptake in rats and mice: practical implications for exercise training. Eur J Cardiovasc Prev Rehabil. 2007;14(6):753-60. https://doi.org/10.1097/ HJR.0b013e3281eacef1.

20. Rahmati-Ahmadabad S, Azarbayjani M, Nasehi M. The effects of highintensity interval training with supplementation of flaxseed oil on BDNF mRNA expression and pain feeling in male rats. Ann Appl Sport Sci. 2017;5(4):1-12.

21. Daskalopoulou SS, Cooke AB, Gomez YH, Mutter AF, Filippaios A, Mesfum ET, Mantzoros CS. Plasma irisin levels progressively increase in response to increasing exercise workloads in young, healthy, active subjects. Eur J Endocrinol. 2014;171(3):343-52. https://doi.org/10.1530/EJE-14-0204.

22. Bostrom P, WU J, Jedrychowski MP, Korde A, Ye L, Lo JC, Rasbach KA, Bostrom EA, Choi JH, Long JZ, Kajimura S, Zingaretti MC, Vind BF, Tu H, Cinti S, Hojlund K, Gygi SP, Spiegelman BM. A PGC1-alpha-dependent myokine that drives brown-fat-like development of white fat and thermogenesis. Nature. 2012;481(7382):463-8. https://doi.org/10.1038/nature10777.

23. Huh JY, Panagiotou G, Mougios V, Brinkoetter M, Vamvini MT, Schneider BE, Mantzoros CS. FNDC5 and irisin in humans: I. Predictors of circulating concentrations in serum and plasma and II. mRNA expression and circulating concentrations in response to weight loss and exercise. Metabolism. 2012;61(12):1725-38. https://doi.org/10.1016/j. metabol.2012.09.002.

24. Chavanelle V, Boisseau N, Otero YF, Combaret L, Dardevet D, Montaurier C, Delcros G, Peltier SL, Sirvent P. Effects of high-intensity interval training and moderate-intensity continuous training on glycaemic control and skeletal muscle mitochondrial function in db/db mice. Scientific Rep. 2017;7(1):204. https://doi.org/10.1038/s41598-017-00276-8.

25. Dinas $P C$, Lahart IM, Timmons JA, Svensson P-A, Koutedakis Y, Flouris AD, Metsios GS. Effects of physical activity on the link between PGC-1a and FNDC5 in muscle, circulating Irisin and UCP1 of white adipocytes in humans: a systematic review. F1000Res. 2017;6:286. https://doi.org/10.12688/f1000research.11107.2.

26. Panati $K$, Suneetha $Y$, Narala VR. Irisin/FNDC5--an updated review. Eur Rev Med Pharmacol Sci. 2016;20(4):689-97.

27. Tiano JP, Springer DA, Rane SG. SMAD3 negatively regulates serum irisin and skeletal muscle FNDC5 and peroxisome proliferator-activated receptor gamma coactivator 1-alpha (PGC-1alpha) during exercise. J Biol Chem. 2015; 290(12):7671-84. https://doi.org/10.1074/jbc.M1 14.617399.

28. Ghanbari-Niaki A, Rahmati-Ahmadabad S, Ansari-Pirsaraei Z. Effects of aerobic training on tissue nesfatin-1/nucleobindin-2 mrna, plasma nesfatin-1 and highdensity lipoprotein concentration in female rats. IJHPA. 2013;4(2):1-7.

29. Dore R, Levata L, Lehnert H, Schulz C. Nesfatin-1: functions and physiology of a novel regulatory peptide. J Endocrinol. 2017;232(1):R45-65. https://doi. org/10.1530/JOE-16-0361.

30. Ge J-F, Xu Y-Y, Qin G, Peng Y-N, Zhang C-F, Liu X-R, Liang L-C, Wang Z-Z, Chen F-H. Depression-like behavior induced by Nesfatin-1 in rats: involvement of increased immune activation and imbalance of synaptic vesicle proteins. Front Neurosci. 2015;9:429. https://doi.org/10.3389/fnins. 2015.00429. 
31. Ayada C, Toru U, Korkut Y. Nesfatin-1 and its effects on different systems. Hippokratia. 2015;19(1):4-10.

32. Khalili S, Shekari Khaniani M, Afkhami F, Mansoori Derakhshan S. NUCB2/ Nesfatin-1: a potent meal regulatory hormone and its role in diabetes. Egyptian J Med Hum Genet. 2017;18(2):105-9. https://doi.org/10.1016/j. ejmhg.2016.10.003.

33. Kadoglou NP, Perrea D, Iliadis F, Angelopoulou N, Liapis C, Alevizos M. Exercise reduces resistin and inflammatory cytokines in patients with type 2 diabetes. Diabetes Care. 2007;30(3):719-21. https://doi.org/10. 2337/dc06-1149.

34. Balducci S, Zanuso S, Nicolucci A, Fernando F, Cavallo S, Cardelli P, Fallucca S, Alessi E, Letizia C, Jimenez A, Fallucca F, Pugliese G. Anti-inflammatory effect of exercise training in subjects with type 2 diabetes and the metabolic syndrome is dependent on exercise modalities and independent of weight loss. Nutr Metab Cardiovasc Dis. 2010;20(8):608-17. https://doi. org/10.1016/j.numecd.2009.04.015.

35. Jamali E, Asad M, Rasoli A. The effect of high-intensity interval training (HIIT) on resistin gene expression in visceral adipose tissue in obese male rats. Int J Appl Exer Physiol. 2016;5(1):17-25.

36. Khadir A, Tiss A, Abubaker J, Abu-Farha M, Al-Khairi I, Cherian P, John J, Kavalakatt S, Warsame S, Al-Madhoun A, Al-Ghimlas F, Elkum N, Behbehani K, Dermime S, Dehbi M. MAP kinase phosphatase DUSP1 is overexpressed in obese humans and modulated by physical exercise. Am J Physiol Endocrinol Metab. 2015;308(1):E71-83. https://doi.org/10. 1152/ajpendo.00577.2013.

37. Patti AM, Toth PP, Giglio RV, Banach M, Noto M, Nikolic D, Montalto G, Rizzo M. Nutraceuticals as an important part of combination therapy in Dyslipidaemia. Curr Pharm Des. 2017;23(17):2496-503. https://doi.org/10. 2174/1381612823666170317145851

38. Giordano P, Scicchitano P, Locorotondo M, Mandurino C, Ricci G, Carbonara S, Gesualdo M, Zito A, Dachille A, Caputo P, Riccardi R, Frasso G, Lassandro G, Di Mauro A, Ciccone MM. Carotenoids and cardiovascular risk. Curr Pharm Des. 2012:18(34):5577-89.

39. Izzo R, de Simone G, Giudice R, Chinali M, Trimarco V, De Luca N, Trimarco B. Effects of nutraceuticals on prevalence of metabolic syndrome and on calculated Framingham risk score in individuals with dyslipidemia. J Hypertens. 2010;28(7):1482-7. https://doi.org/10.1097/HJH. 0b013e3283395208.

40. DeFelice SL. The nutraceutical revolution: its impact on food industry R\&D. Trends Food Sci Technol. 1995;6(2):59-61. https://doi.org/10.1016/ S0924-2244(00)88944-X.

41. Ansari S, Djalali M, Mohammadzadeh Honarvar N, Mazaherioun M, Zarei M Agh F, Gholampour Z, Javanbakht MH. The effect of $n-3$ polyunsaturated fatty acids supplementation on serum Irisin in patients with type 2 diabetes: a randomized, double-blind, placebo-controlled trial. Int J Endocrinol Metab. 2017;15(1):e40614. https://doi.org/10.5812/ijem.40614.

42. Vaughan RA, Garcia-Smith R, Bisoffi M, Conn CA, Trujillo KA. Conjugated linoleic acid or omega 3 fatty acids increase mitochondrial biosynthesis and metabolism in skeletal muscle cells. Lipids Health Dis. 2012;11:142. https:// doi.org/10.1186/1476-511X-11-142.

43. Tortosa-Caparros E, Navas-Carrillo D, Marin F, Orenes-Pinero E. Antiinflammatory effects of omega 3 and omega 6 polyunsaturated fatty acids in cardiovascular disease and metabolic syndrome. Crit Rev Food Sci Nutr. 2017:57(16):3421-9. https://doi.org/10.1080/10408398.2015.1126549.

44. Mostowik M, Gajos G, Zalewski J, Nessler J, Undas A. Omega-3 polyunsaturated fatty acids increase plasma adiponectin to leptin ratio in stable coronary artery disease. Cardiovasc Drugs Ther. 2013;27(4):289-95. https://doi.org/10.1007/s10557-013-6457-x.

Ready to submit your research? Choose BMC and benefit from:

- fast, convenient online submission

- thorough peer review by experienced researchers in your field

- rapid publication on acceptance

- support for research data, including large and complex data types

- gold Open Access which fosters wider collaboration and increased citations

- maximum visibility for your research: over $100 \mathrm{M}$ website views per year

At BMC, research is always in progress.

Learn more biomedcentral.com/submissions 